on the genetics of neuromuscular disease, and on myasthenia and myotonia. There is an important chapter on chronic progressive disorders of the lower motor neuron by Gamstorp and the late Professor Gunnar Wohlfart.

The final part consists of a selection of experimental techniques likely to yield results of interest in the study of neuromuscular disorders in the future, including tissue culture, microelectrode studies of membrane potential in man, and the measurement of refractory period, enzyme studies and fluorescent antibody techniques.

In the field of neuromuscular disorders, substantial additions to our knowledge have been made in recent years, partly by clinical and histopathological analysis and partly by the introduction of new laboratory techniques. This volume, although not giving a complete coverage of the field, has gathered together a considerable number of valuable contributions by many of those who have been responsible for these advances.

\section{Advances in Biology of Skin, Vol. 2, Blood Vessels and Circulation}

Editors: W. Montagna, and R. A. Ellis, Pp. I56, illustrated. Oxford, London, New York, Paris: Pergamon Press. 1961. £.3 35 .

This book presents the proceedings of the Brown University Symposium on the Biology of the Skin, held in 1960. There are thirteen contributors to its nine chapters. It opens with two chapters on vascular patterns, the first by Winkelmann and his colleagues on India ink injection and alkaline-phosphatase reaction studies, the second by Ellis based on thick frozen section alkaline phosphatase studies. Other chapters deal with capillary microscopy, X-ray projection microscopy and electron microscopy. There is a short chapter by Weddell on innervation of cutaneous blood vessels and a longer one by Hertzman on the effects of heat on cutaneous blood flow. In a chapter on special features of the circulation of the skin, Burton concludes that the subservience of the requirements of the skin cells, with respect to control of their circulation, to the service of the whole organism may render them peculiarly susceptible to ischæmia in diseased states. Urbach in his chapter on the blood supply of tumours speculates on carcinogenesis and offers a 'unified' theory based on Pasteur's 'Life without Air is the Key to the problem of Cancer'.

This well illustrated book is, perhaps, of greater interest to the laboratory worker and experimentalist than to the practising physician, but it indicates the likely lines of further research in this important field. It should certainly be in all medical libraries.

\section{Medicine in Tropical Africa}

Michael Gelfand, C.B.E., M.D., F.R.C.P., D.P.H., D.M.R. Pp. 243 , illustrated. Edinburgh and London: E. \& S. Livingstone. 1961. 30s.

Dr. Gelfand has not only made many valuable contributions to periodicals largely concerned with tropical medicine; he is also a prolific writer on medical and para-medical subjects that impinge upon medical practice in Central Africa.

In the present volume, he has taken a step back from the bedside, and has stood and stared at the clinical and epidemiological problems confronting the thoughtful practitioner in the tropics, bringing a mature and res flective mind to bear upon the wealth of clinical exo perience at his disposal and the fruit of wide reading His main purpose is to view the 'sick African' in his various settings, and to assess the interplay of hereditary and nutritional factors, of parasitic infection-ofters. multiple - and of a multiplicity of static and changing environments.

This is not a book for the beginner-it presumes certain amount of factual knowledge of tropical diseases $\frac{}{0}$ but it is intended for the practitioner in town or bush ir tropical Africa who realizes his need for orientation? Too frequently, specialists have insisted that the " $\operatorname{wood} \mathbb{D}$ consists exclusively of their own pet ' trees', to the conto fusion of the doctor in daily touch with sick individuals, and to the detriment-be it admitted - of the patients who may indeed harbour this or that parasite, but whose total clinical condition may be due to either $\vec{q}$ multiplicity of parasitological infections or to une suspected and extraneous conditions.

Not all will agree with . every statement of Dio Gelfand's, and some will suggest that here and there the emphasis is somewhat misplaced or one-sided. But thi is an individual book, and no reader will fail to profit from the stimulating and provocative presentation of many practical problems.

The photographs are very well reproduced, but the text is unfortunately marred by many misprints and mis-spellings.

Lectures on the Methodology of Clinical Research

Max. Hamilton, M.D., D.P.M. Pp. viii $+\mathrm{r} 39$ 疋 illustrated. Edinburgh and London: E. \& S S Livingstone. 1961. $21 s$.

The set of lectures on which this book is based sprof from the author's opinion that 'clinical practice needs much more science than it has had heretofore. It is க⿳亠丷厂 sufficient for the clinician to rely on his empiriag " experience" and ability to understand the patient as at human being, leaving the "science" to specialists and technicians'. Since I 953 the lectures have been giverof annually to an audience which included 'physicians surgeons, obstetricians, anæsthetists, clinical pathologists

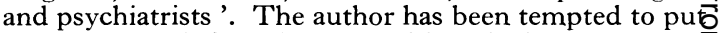
them into book form because, although there are man 3 excellent books on statistical methods and the design of experiments, there are few that deal directly with the्ठ problems of clinical medicine.

The result is a short book with a strong individuap flavour and one which can be heartily recommended to clinicians who wish to get an idea of the principles tha? underly experimental design and the various tests of statistical significance. As the author is himself a clinicab research worker, he is able to discuss various medicap situations in a way which is understandable to other doctors, and it is this which gives the book its speciaf value.

Although the author writes plainly, it must not beo supposed that this is a book which any doctor will finde easy to read, because our standard of clinical educatior is so lacking in scientific method that most doctors find difficulty in grasping the most elementary statistica 5 concepts. Nevertheless, if they persist with this bookN they are bound to gain some understanding of the powerful and elegant methods that are available for solving clinical problems. The book does not take tho place of standard textbooks of statistical methods, but if does serve as an admirable introduction to them. 